\title{
A experiência da paternidade ao final do primeiro ano de vida do bebê
}

\author{
Evandro de Quadros Cherer \\ Universidade de Brasília, DF, Brasil \\ Joice Cadore Sonego \\ FSG Centro Universitário, RS, Brasil \\ Cesar Augusto Piccinini \\ Rita de Cássia Sobreira Lopes \\ Universidade Federal do Rio Grande do Sul, RS, Brasil
}

\begin{abstract}
Resumo
O presente estudo investigou a experiência da paternidade ao final do primeiro ano de vida do bebê. Participaram 35 pais primíparos que eram de níveis socioeconômicos variados e residiam na região metropolitana de Porto Alegre. Os pais foram entrevistados individualmente e suas verbalizações foram analisadas através da análise de conteúdo em três categorias: $O$ pai e a experiência da paternidade, O filho e a experiência da paternidade e $A$ esposa e a experiência da paternidade. Os resultados indicaram que a experiência da paternidade, no final do primeiro ano de vida do bebê, esteve associada a sentimentos de satisfação, sendo que os pais mostraram-se bastante participativos e envolvidos na vida familiar, assim como nos cuidados com o bebê. Todavia, ainda que muitas vezes de forma sutil e contraditória, os participantes expressaram certa ambivalência frente à experiência da paternidade com seu primeiro filho, demandando dos pais um reposicionamento frente à vida.
\end{abstract}

Palavras-chave: Experiência da paternidade; Paternidade; Relação pai-bebê.

\section{The experience of fatherhood by the end of the infant's first year of life}

\section{Abstract}

In this study we investigated the experience of fatherhood by the end of the infant's first year of life. A total of 35 primiparous fathers, who were of different socioeconomic backgrounds and lived in the metropolitan region of Porto Alegre, took part in this study. They were individually interviewed and their responses were grouped, after a qualitative content analysis, into three categories: Himself as father and the experience of fatherhood, His child and the experience of fatherhood, His wife and the experience of fatherhood. The results indicated satisfaction with fatherhood, and fathers were shown to be very involved in family life, as well as in baby care. Nevertheless, the experience of fatherhood was also associated with some difficulties, which enables one to think about how this experience may be ambivalent.

Keywords: Experience of fatherhood; Fatherhood; Father-infant relationship.

\section{La experiencia de la paternidad al final del primer año de vida del bebé}

\section{Resumen}

El estudio investigó la experiencia de la paternidad a los 12 meses del bebé. Eran parte 35 padres primíparos que eran de diferentes niveles socioeconómicos y vivían en la región metropolitana de Porto Alegre. Ellos fueron entrevistados individualmente y sus declaraciones fueron analizados por análisis de contenido en tres categorías: El padre y la experiencia de la paternidad, El hijo y la experiencia de la paternidad, La esposa y la experiencia de la paternidad. Los resultados indicaron que la experiencia de la paternidad, a los 12 meses del bebé, se asoció con un sentimiento de satisfacción y los padres eran muchos participativos y involucrados en la vida familiar, así como en el cuidado del bebé. Sin embargo, aunque a menudo sutiles y contradictorias, los participantes expresaron cierta ambivalencia hacia adelante a la experiencia de la paternidad de su primer hijo, los padres exigiendo un reposicionamiento frente a la vida.

Palabras clave: Experiencia de la paternidad; Paternidad; Relación padre-hijo. 


\section{Introdução}

Tornar-se pai ou mãe concerne a uma vivência que não se restringe ao fato de ter um filho, mas também implica em experiências e transformações que abrangem diversos aspectos da vida. Com relação ao tornar-se pai, sobretudo no que diz respeito aos aspectos subjetivos da paternidade, os estudos são ainda muito escassos (Jager \& Bottoli, 2011; Houzel, 2004). No entanto, o fenômeno da paternidade e suas repercussões na vida do homem têm ganhado maior interesse dos autores que procuram investigar a transição do homem para a paternidade (Cherer, Ferrari, \& Piccinini, 2016; Chin, \& Daiches, 2011; Eerola, \& Huttunen, 2011; Guzzo, 2011; MacAdam, Huuva, \& Berterö, 2011).

Entre as diversas perspectivas possíveis no entendimento desse fenômeno, a partir da psicanálise se considerou os assinalamentos propostos por Houzel (2004) sobre os três eixos da parentalidade que abrangem o conjunto das funções e papéis parentais desempenhados pelo pai, e também pela mãe, a saber, exercício, experiência e prática da parentalidade. O exercício da parentalidade tem relação com os direitos e deveres dos genitores, abrangendo os aspectos jurídicos. A experiência da parentalidade diz respeito aos aspectos subjetivos conscientes e inconscientes do processo de vir a ser pai ou mãe e de ocupar os papéis parentais. Por sua vez, a prática da parentalidade se refere aos cuidados físicos e psíquicos desempenhados cotidianamente com o filho. No presente estudo, se buscou focar apenas o segundo eixo da experiência da paternidade com base no conceito proposto por Houzel $(2004)^{1}$.

Ao encontro dessas ideias, compreende-se que a experiência da paternidade engloba diversos aspectos, entre esses o desejo pelo filho e o processo de tornarse pai (Houzel, 2004). Quanto ao desejo, para Freud (1914/2004) a paternidade está relacionada a uma expectativa de imortalidade, como se parte do genitor permanecesse viva no filho. Para além de querer que algo de si viva no outro, Freud (1923/1990) também considerou que as resignações decorrentes da vida distanciam o humano de um ideal almejado, demarcando sempre existir um hiato em relação àquilo que se deseja. Visto isso, considera-se que, se uma criança vem ao mundo, é porque, em certa medida, faz falta a alguém, isto é, um filho para um adulto

\footnotetext{
1 Em outro artigo de autoria de Polli, Gabriel, Piccinini e Lopes (2016), as falas dos pais do presente estudo foram examinadas em relação à prática da paternidade com base no conceito de envolvimento que abrange a interação, acessibilidade e responsabilidade paterna em relação ao filho. Esses aspectos têm sido investigados inclusive em outros estudos brasileiros (Castoldi, Gonçalves, \& Lopes, 2014; Piccinini, Silva, Gonçalves, Lopes, \& Tudge, 2012).
}

representa aquilo que lhe falta. A criança, mais do que um descendente, corresponde a uma promessa (Freud, 1923/1990). Por esta razão um pai pode encontrar grande satisfação em seu filho, visto que a criança representa a possibilidade de realização dos desejos paternos. Com efeito, o bebê pode proporcionar um aumento no sentimento de autoestima, tanto pela satisfação e prazer pelo fato de o homem ter se tornado pai, quanto por ter sido capaz de ter um bebê.

No que se refere ao processo de tornar-se pai, compreende-se que a paternidade não corresponde a um evento pontual e limitado. Ao contrário, trata-se de uma transição lenta e gradual, cujo início se reporta à própria infância do pai e as suas relações parentais (Bouchard, 2012; Cherer, Ferrari, \& Piccinini, 2016), iniciando antes mesmo do nascimento do bebê (Brazelton \& Cramer, 1992; Parke, 1996) e que prossegue ao longo do desenvolvimento da criança (MacAdam et al., 2011). Além disso, a paternidade conduz o homem a reposicionar-se na cadeia intergeracional, assim como a reorganizar seu lugar na relação conjugal. De fato, o pai passa por questionamentos, bem como por um remanejamento pulsional com a chegada do bebê (Chevalerias, 2005; Hurstel, 2006). A paternidade, especialmente ao se ter o primeiro filho, demanda diversas adaptações daqueles que a vivenciam (Höfner, Schadler, \& Richter, 2011). Desse modo, tornar-se pai não é um evento único, mas um processo de ocupar esse novo posicionamento, o qual pode ser vivenciado de diversas formas, que a partir da história singular de cada homem pode ser experienciado como prazeroso, mas também difícil e estressante (Gonçalves, Guimarães, Silva, Lopes, \& Piccinini, 2013; Parke, 1996).

Os aspectos subjetivos da experiência da paternidade têm sido estudados em diversos contextos e etapas do desenvolvimento do bebê. O período da gestação, no estudo de Krob, Piccinini e Silva (2009), foi essencialmente associado a um momento de desenvolvimento da ideia de ser pai, sendo permeado por expectativas e antecipações sobre a paternidade. Aos três meses de vida do bebê, o estudo de Gonçalves et al. (2013), evidenciou que os pais ${ }^{2}$ associaram à experiência da paternidade particularmente a sentimentos de satisfação. Dificuldades, como, por exemplo, nos cuidados com o bebê, também foram relatadas, no entanto, de modo a incluir o bebê em suas vidas, esses pais buscavam reequilibrar ganhos e renúncias em relação à paternidade. Além disso, os autores inferiram ser possível pensar que a paternidade

\footnotetext{
2 Neste artigo, o termo "pais" é empregado especificamente para designar o plural de "pai". Quando necessário, os termos "pai(s) e mãe(s)" ou "genitores" serão utilizado para designar ambos. Já o termo "filho" é utilizado independentemente do sexo do bebê.
} 
foi relatada de forma idealizada, sendo que eventuais aspectos negativos seriam encobertos ou evitados de serem narrados.

Isso tudo faz com que a paternidade seja uma experiência complexa, a qual acarreta no homem diversas repercussões subjetivas e sociais, como mudanças na percepção de si, na relação conjugal e na cadeia intergeracional, além de ocasionar aumento de responsabilidades, demandando a ocupação de novos papéis (Dallos \& Nokes, 2011; Premberg, Hellström \& Berg, 2008). Contudo, mesmo diante do crescimento dos estudos sobre paternidade, percebe-se ainda uma escassez de estudos qualitativos que abordem a experiência da paternidade. Essencialmente, investigações que contemplem as experiências subjetivas de homens no processo de se tornarem pais. Ademais, se faz importante que esses estudos possam contemplar as especificidades de cada etapa do desenvolvimento da criança e, por conseguinte, do processo de tornar-se pai. Assim, o presente estudo teve como objetivo investigar a experiência da paternidade no primeiro ano de vida do bebê. Este estudo complementa outro já realizado com os mesmos participantes, mencionado acima, aos três meses (Gonçalves et al., 2013). Acredita-se que o conjunto desses estudos permitirá avançar rumo a uma melhor compreensão dos aspectos subjetivos implicados na experiência da paternidade em várias etapas do desenvolvimento da criança.

\section{Método}

\section{Participantes}

Participaram deste estudo 35 pais que tiveram seu primeiro filho, com idades entre 19 e 41 anos $(M=22,7$ anos; $D P=6,5)$. Todos viviam com a mãe do bebê que também era primípara. $\mathrm{Na}$ ocasião das entrevistas, os bebês tinham aproximadamente um ano de vida e não apresentavam problemas de saúde. Os pais eram de níveis socioeconômicos variados e residiam na região metropolitana de Porto Alegre. Com relação à escolaridade, a maioria dos participantes tinha ensino superior (completo: 17,1\%; incompleto: $14,2 \%$; pósgraduação: $5,7 \%$ ). Os demais variavam entre ensino fundamental incompleto $(17,1 \%)$ e completo $(8,5 \%)$, ensino médio completo $(31,4 \%)$ e incompleto $(5,7 \%)$.

Todos os participantes do presente estudo foram selecionados dentre os participantes do projeto intitulado Estudo Longitudinal de Porto Alegre: Da Gestação à Escola - ELPA (Piccinini, Tudge, Lopes, \& Sperb, 1998-2012). Com exceção dos dados sociodemográficos coletados na gestação e atualizados no $12^{\mathrm{O}}$ mês, o presente estudo considerou apenas dados obtidos no
$12^{\mathrm{O}}$ mês de vida da criança, tendo sido incluídos todos os pais que atendiam aos critérios do estudo e que tinham dados completos disponíveis. O projeto recebeu aprovação do Comitê de Ética da UFRGS (n-0 2006596).

\section{Procedimentos e instrumentos}

Os pais foram convidados para participar do estudo ainda durante a gravidez da companheira. Nessa etapa, a família era informada a respeito dos objetivos do estudo e respondia a Ficha de contato inicial, a qual buscava verificar o preenchimento dos critérios de inclusão na amostra. Era então marcado um encontro na residência dos participantes, quando a mãe e o pai assinavam o Termo de Consentimento Livre e Esclarecido e respondiam à Entrevista sobre dados demográficos da família, usada para obter informações adicionais, como idade, escolaridade, estado civil etc ${ }^{3}$.

As famílias foram novamente contatadas quando o bebê completava três e doze meses de vida. Nessa última etapa, os pais responderam à Entrevista sobre a Experiência da Paternidade e o Desenvolvimento do Bebê no Primeiro Ano. Essa entrevista estruturada, realizada de forma semidirigida, procurava examinar, dentre outras questões, as impressões do pai em relação ao filho, seu desenvolvimento e temperamento, seus próprios sentimentos e dificuldades enquanto pai, o dia a dia do pai com o bebê, que tarefas assumia nos cuidados com o filho, tipos de brincadeiras que fazia e as suas percepções sobre a companheira como mãe. A entrevista tinha a duração de aproximadamente uma hora, era gravada e, posteriormente, transcrita.

\section{Resultados}

Após a transcrição e leitura das entrevistas, procedeu-se à categorização dos conteúdos através de análise de conteúdo qualitativa (Laville \& Dione, 1999), contemplando três categorias destacadas na literatura sobre paternidade (Gonçalves et al., 2013; Houzel, 2004; Krob et al., 2009), a saber: O pai e a experiência da paternidade, O filho e a experiência da paternidade e A esposa e a experiência da paternidade. Dois autores do presente estudo classificaram, por consenso, todos os relatos dos pais nestas categorias. A seguir, cada uma destas categorias será caracterizada e ilustrada com relatos dos próprios pais.

\section{O pai e a experiência da paternidade}

Essa categoria envolve os relatos dos pais sobre suas impressões, sentimentos, expectativas, dificuldades,

\footnotetext{
3 Diversos outros instrumentos foram utilizados na coleta de dados, conforme Piccinini, Tudge, Lopes, e Sperb (1998-2012), mas destacam-se aqui apenas aqueles cujos dados foram usados no presente estudo.
} 
bem como a descrição e a avaliação de si mesmos como pais no final do primeiro ano de vida do filho. No presente estudo, a maioria ${ }^{4}$ dos pais $(68 \%)$ relacionou a paternidade a sentimentos prazerosos, descrevendo como uma experiência "boa", "legal", "gratificante" e "maravilhosa". Também relataram sentimentos de felicidade, completude e de bem-estar: "Está sendo ótimo, eu acho que é o ápice do ser humano ser pai" (P34). Alguns pais (14\%) acrescentaram que além dos sentimentos prazerosos, a paternidade também seria uma experiência trabalhosa e até cansativa: "Está sendo ótimo e ao mesmo tempo cansativo" (P33).

No que diz respeito às expectativas que os pais tinham, alguns deles (14\%) relataram que a experiência da paternidade os estava surpreendendo, sendo inclusive mais prazerosa do que eles esperavam: "Eu imaginava que fosse ser bom, mas não tão bom" (P26). Outros (11\%) tinham inclusive imaginado que a paternidade seria mais difícil do que de fato foi para eles: "Achava que ia ser mais difícil, mas não, não é tão assim" (P17). Três participantes expressaram explicitamente que tinham o desejo de ter filhos, sendo a paternidade parte do seu próprio projeto de vida: " $E u$ sempre tive uma boa impressão de ter filho, sempre tive a vontade de ter, sempre fez parte dos meus planos, do projeto de vida da gente, mas é bem melhor" (P15). Por sua vez, outros dois pais descreveram que a experiência da paternidade estava dentro de suas expectativas: "Pra mim é uma coisa quase que normal, não sei se eu é que me adaptei bem, ou tá dentro do cotidiano, tá dentro daquilo que eu esperava" (P16).

Apesar disto, alguns pais (20\%) também discorreram acerca das alterações em suas vidas com o nascimento de seus filhos, destacando que a paternidade trouxe intensas mudanças de vida, o que exigiu inclusive reorganização de diversos aspectos: "[A paternidade] é uma coisa maravilhosa, muda radicalmente a vida da gente, mas a gente se adapta a cada fase, a cada circunstância" (P25). Em relação a isso, três pais relataram a sensação de maior responsabilidade em suas vidas: "Vem um pacote inteiro, vem preocupação, vem responsabilidade" (P22). Em contrapartida, um pai falou que sua vida continuaria da mesma forma: "A gente tem que continuar a vida normalmente e ele [filho] inserido nisso ai" (P30).

Contudo, para vários pais (34\%), a paternidade estava associada a algumas dificuldades. Entre essas, alguns pais (14\%) se referiram às limitações de tempo na relação com o filho como a principal dificuldade

\footnotetext{
$4 \mathrm{Na}$ descrição dos achados serão usados os seguintes termos: poucos/ alguns (1-7 pais), vários (8-14 pais), muitos (15-21 pais), maioria (22-28 pais), grande maioria (29-35 pais). A autoria das vinhetas é identificada pela letra 'P' seguida do número do caso.
}

experienciada por eles, com potencial impacto na própria paternidade: "Eu tenho dificuldade é na questão de tempo, que é difícil, mas em outros aspectos não. Só o tempo, tinha que ter mais tempo" (P29). Outros pais atribuíram suas dificuldades a fatores como, por exemplo, falta de paciência com o filho $(11 \%)$, dificuldade em educar o filho (5\%) e um caso referiu ter dificuldade quando o filho adoecia e o pai não sabia como proceder. Alguns pais (11\%) relataram não terem dificuldades com a paternidade: "Tudo foi bem desde a gravidez, até os dias de hoje, eu não tive nenhuma dificuldade (...) não teve nada de anormal, tudo dentro do esperado" (P16). Enfatizando isto, um pai relatou que para ele a paternidade "estava sendo fácil" (P22).

Outro aspecto relevante no relato dos participantes foi que muitos $(51 \%)$ se consideravam bons pais. Alguns deles (22\%) afirmaram que eram participativos e presentes na criação dos filhos: "Eu acho que eu sou um bom pai, resumindo assim, eu brinco, eu dou atenção pra ela, às vezes eu saio com ela no sábado só nós dois pra passear" (P33); "Eu acho que ser pai é participar, tem que estar presente, ajudando a educar. Isso é bom, ainda bem que eu estou fazendo" (P34). Ainda entre os que se descreveram como bons pais, alguns $(11 \%)$ vincularam essa avaliação a não deixar faltar nada para seus filhos: "Eu acho que eu sou um bom pai, nunca deixei faltar nada pra ele" (P28). Além disso, dois dos participantes associaram o ser bons pais com o fato de serem preocupados com a filha: "Muito preocupado com ela" (P25). Outros participantes $(11 \%)$, ainda que não tenham se denominado como bons pais, descreveram-se como afetivos, atenciosos e "corujas": "Eu acho que sou um pai afetivo, que tento participar" (P26). Por sua vez, alguns pais (11\%) descreveram a si mesmos como orgulhosos: "Eu me sinto orgulhoso. Esse serzinho, assim, do tamanho dela, é tão importante, e pensar que foi você que ajudou a fazer" (P25). Por fim, alguns pais não pareciam muito satisfeitos consigo mesmos e destacaram que eram, por exemplo: "pai normal" (P4); "faltando muito para ser excelente" (P6); "sistemático e fechado" (P35); e, mesmo um "pai ausente" (P19).

\section{O filho e a experiência da paternidade}

Esta categoria diz respeito aos relatos dos pais sobre as impressões e sentimentos sobre o filho, com destaque para o seu desenvolvimento físico e emocional, seu jeito de ser, o dia a dia com o filho, e como isso estava relacionado à paternidade no final do primeiro ano de vida do filho. Em relação ao desenvolvimento, a maioria dos pais (65\%) destacou as novas habilidades adquiridas por ele, que os deixava, muitas vezes, surpresos com o filho: "Cada dia que 
passa é uma surpresa" (P1); "Ele tem surpreendido a gente a cada dia, ele tá fazendo coisas que a gente, eu e $a R$. [esposa] pensava que ele ia fazer mais tarde" (P8). Além disso, muitos pais (51\%) verbalizaram estarem se sentindo bem, alegres e gratificados com essas mudanças: "Essas coisas que a criança, ela mesma vai descobrindo e vai proporcionando pra gente que tá em volta dele. Então isso é uma coisa gratificante" (P34). Ainda, alguns pais (22\%) relacionaram essa experiência de satisfação ao ver o filho começar a ensaiar os primeiros passos: "Eu tava louco pra ver ele caminhar, pequeninho né, bonitinho, eu queria ver como era. Quando eu menos esperei ele já tava caminhando" (P27).

Vários participantes (34\%) também destacaram diversas características do filho consideradas positivas por eles, como ser inteligente, sociável, amoroso, alegre: "Esperta, muito esperta, alegre" (P32). Quanto ao jeito de ser do filho, cinco pais salientaram que eles já mostravam características consideradas intensas: "Ela tem a opinião dela e se impõe" (P4). Alguns pais $(20 \%)$, inclusive, relataram o quanto o filho era parecido com as expectativas que eles tinham: "Ela é como eu imaginava" (P12). Outros (20\%) verbalizaram que o filho era diferente do que eles imaginavam: "Eu achei que ele fosse ser um pouco mais mal humorado" (P61); enquanto dois pais disseram que não tinham expectativas quanto ao bebê: "Não criei expectativa" (P35).

Vários pais $(40 \%)$ destacaram que estava mais fácil e prazeroso interagir com o filho nesta etapa do desenvolvimento, especialmente por esse estar mais autônomo e se comunicar melhor: "Depois de um ano, agora, é muito mais tranquilo, né, muito mais seguro, sabe? Porque ela tem autonomia, ela já tá caminhando, ela já sabe se expressar mais" (P25). Contudo, três dos participantes disseram que era mais fácil quando a criança era mais nova: "Agora é bem pior, porque ela não pára" (P20). Por sua vez, um dos pais também fez comparações do desenvolvimento do filho com o de outras crianças, considerando que o bebê estava se desenvolvendo melhor ou mais rápido que outros da mesma idade: "Um crescimento emocional, mobilidade, melhor que muitas crianças aí que a gente conhece" (P35).

A maioria dos pais $(65 \%)$ realizou comparações das características dos filhos com eles mesmos: "Eu acho ele mais parecido comigo né, o gênio dele, quando ele quer alguma coisa, ele põe a boca no mundo e é como ele quer, e eu sou bem parecido" (P28). Vários pais (25\%), inclusive, mostraram-se felizes, satisfeitos e orgulhosos com o fato de os filhos terem traços semelhantes aos deles, seja com relação a aspectos físicos e ao temperamento: "O cheirinho dela é igual ao cheirinho do pai, não tem melhor que isso" (P25); "É legal dizerem, 'ah é tua cara', é bom" (P33). Por sua vez, vários pais (28\%) compararam características de seus filhos com as de suas esposas: "O jeito assim, de brabo, tudo é a mãe" (P34). Além disso, outros (14\%) também compararam o bebê com os demais membros da sua família de origem: "É brabo, que nem o meu irmão" (P32).

No tocante ao dia a dia com seus filhos, os pais se mostraram, na sua maioria $(80 \%)$, bastante participativos nos cuidados com o bebê : "Eu tô sempre junto" (P33), embora vários (28\%) não dispunham do tempo que gostariam para estarem com o filho devido ao trabalho: "Nem sempre eu posso conciliar as minhas coisas" (P34); e, por isso, dispunham mais tempo à noite ou nos finais de semana: "Fim de semana muda completamente porque ai de manhã, principalmente, eu fico com ela" (P35). Os pais referiram então, as atividades que gostavam ou não de fazer com os filhos, sendo que a maioria dos pais $(71 \%)$ relatou gostar de brincar, de preferência brincadeiras mais ativas $(60 \%)$ : "Eu gosto de deitar com ele [filho], ele vem por cima de mim" (P30); "É brincar com ela, fazer ela dar risada e ficar observando ela descobrindo as coisas" (P4); assim como em passear com o filho (22\%): "Eu gosto de passear com ele, ele gosta" ( $\mathrm{P} 8)$. Por sua vez, vários pais $(34 \%)$ relataram não gostar de trocar fraldas ou a roupa da criança: "Me incomoda trocar a fralda dela" (P25).

\section{A esposa e a experiência da paternidade}

Esta categoria abrange os relatos dos pais sobre sua experiência da paternidade em associação ao relacionamento conjugal e à companheira enquanto mãe. Em relação à organização da rotinha com o filho, muitos pais (48\%) destacaram que dividiam de modo igualitário com a esposa os cuidados com o bebê, se mostrando bastante satisfeitos com isso: " $E u$ tô fazendo meio a meio, eu tô achando bem legal" (P22). Contudo, vários pais (28\%) expressaram que as esposas assumiam a maior parte dos cuidados com o filho. Para esses pais, uma vez que as mães dispunham de mais tempo com o bebê, elas sabiam cuidar melhor do filho. Desse modo, esses pais descreveram-se como auxiliares nos cuidados com os filhos: "É que ela é mãe, ela é mais presente do que eu" (P27); "Eu sou auxiliar" (P24). De qualquer modo, muitos pais participavam de algum modo na rotina de seus filhos, embora vários (42\%) relataram participar em função da solicitação da esposa: "Se ela tá fazendo alguma coisa, ela me pede, eu vou lá e troco, eu procuro ajudar, sempre que ela me pede eu procuro ajudar, mas quem toma conta dele 
mesmo é ela" (P27). Nesse sentido, dois pais inclusive relataram sentirem-se cobrados por suas esposas, o que foi associado às suas limitações em participar dos cuidados com o bebê: "Tem vezes até que ela espera mais de mim, mas tem vezes que a gente também está no limite, né, de ficar, de trabalhar e estar cansado" (P26). Por sua vez, outros pais (37\%) relataram participar por iniciativa própria: "Geralmente, eu me ofereço. Eu pergunto pra ela: 'tu já trocou?', ai ela 'não', 'então deixa que eu troco" (P32).

Além desses aspectos, vários pais (37\%) destacaram que, em certos momentos, havia conflitos com a esposa no que dizia respeito aos cuidados e à educação do filho: "Às vezes eu sou meio duro com ele [bebê] e dai ela [esposa] tenta proteger, isso ai é uma coisa que a gente briga, eu disse 'olha, tô conversando com ele, depois tu espera a gente resolver nossos problemas, depois tu intervém do jeito que tu quiser, mas por enquanto não'. Aì é um estressezinho assim, mas depois a gente resolve" (P14).

\section{Discussão}

Analisados conjuntamente, os relatos dos pais indicaram que a experiência da paternidade, ao final do primeiro ano de vida do bebê, esteve associada a sentimentos de satisfação, assim como algumas dificuldades diante da paternidade, constituindo-se, em certa medida, em uma experiência ambivalente. Para a maioria dos pais do presente estudo, a paternidade foi essencialmente vinculada a sentimentos de satisfação, por meio dos quais os pais expressavam sua autoestima, sentindo-se felizes e orgulhosos. Em consonância com esses achados, a literatura indica que, comumente, os pais vivenciam o sentimento de um grande crescimento pessoal, sobretudo com o nascimento do primeiro filho (Brazelton \& Cramer, 1992; Premberg, Hellström, \& Berg, 2008). Alguns participantes, inclusive, indicaram intensas expressões de alegria, remetendose ao sentimento de extrema exaltação que pode acometer os pais nessa fase, o que, numa perspectiva psicanalítica, pode estar associado aos atributos narcísicos dos quais os filhos foram investidos. Ainda que de forma inconsciente, os pais desejam que o filho realize ambições almejadas por eles. Desse modo, o filho pode ser tomado como um investimento narcísico, por meio do qual o genitor anseia obter aquilo que the falta (Freud, 1914/2004). Com isso, a paternidade pode provocar fantasias de completude, assim como suscitar a sensação de maior propósito na vida (Brazelton \& Cramer, 1992). Nesse cenário, pode-se compreender que essas reações de exaltação são, em alguma medida, efeito de uma idealização acerca da paternidade, a qual pode sustentar-se nas promessas que um filho traz consigo. Com efeito, conforme Leclaire (1977), normalmente a paternidade é engendrada a partir do desejo paterno da criança maravilhosa, aquela que seria desejada a fim de responder os sonhos e desejos infantis parentais.

Em contrapartida, em alguns casos, a paternidade também foi relatada como uma experiência cansativa que envolvia dificuldades, na medida em que os pais se tornaram responsáveis pela vida de seus filhos, adquirindo, com isso, novas responsabilidades (Brazelton \& Cramer, 1992; Fägerskiöld, 2008). A respeito disso, conforme Parke (1996), a paternidade pode se tornar fatigante, difícil e estressante, uma vez que o homem passa a assumir novas atividades para além do seu trabalho e a ter novas preocupações. Nessa perspectiva, os resultados indicaram que a paternidade pode também ser percebida como uma experiência trabalhosa, sobrecarregando o homem (Premberg, Hellström, \& Berg, 2008). Desse modo, ainda que muitas vezes de forma sutil e contraditória, os participantes expressaram a ambivalência pertinente em serem pais de um bebê com um ano de idade, processo esse que evidencia o remanejamento pulsional exigido no processo de tornar-se pai, isto é, a cessão de libido ao se investir psiquicamente no filho, o que provocou mudanças no destino dos investimos pulsionais paternos (Chevalerias, 2005; Hurstel, 2006).

No presente estudo, a maior parte das mudanças associadas à paternidade foi expressa sutilmente por meio das novas rotinas e atividades desempenhadas. Com isso, usualmente, não foi de modo manifesto que os pais relataram passar por questionamentos ou por mudanças pessoais. Esses aspectos vão ao encontro do estudo de Premberg et al. (2008), no qual os pais não manifestaram espontaneamente estarem afetados, ainda que houvesse indícios dessas repercussões. Entretanto, para alguns pais do presente estudo, as mudanças foram vivenciadas como reviravoltas, transformando radicalmente o modo como eles organizavam suas vidas. Dessa maneira, acredita-se que a própria história subjetiva paterna, a expectativa e os planos de vida desenvolvidos pelos pais podem contribuir para o modo como as repercussões da paternidade são vivenciadas por eles (Cherer, Ferrari, \& Piccinini, 2016).

No que diz respeito às expectativas dos pais sobre a paternidade, alguns participantes as associaram manifestamente ao desejo pelo filho como projeto de vida, indicando a relevância do bebê para o desejo paterno, bem como evidenciando a importância da paternidade na organização de suas constituições subjetivas. Isso pode ter acontecido inclusive para os pais que não tenham expressado manifestamente 
essa associação, os quais também sustentariam sua paternidade como um desejo, ainda que de modo inconsciente. Além disso, de forma semelhante ao estudo de Fägerskiöld (2008), alguns pais também se surpreenderam com a paternidade, achando-a mais fácil do que imaginavam ou ainda mais satisfatória do que esperavam.

Quanto à descrição e avaliação de si como pais, os participantes relataram que se considerarem, essencialmente, bons pais. Para eles, as características positivas relacionadas à paternidade foram associadas, principalmente, com ser participativo, prover as necessidades do bebê e, ainda, em se preocupar com o filho. Com isso, percebe-se que, ainda que ser provedor - característica tipicamente vinculada ao pai tradicional - tenha surgido nos relatos paternos, ser participativo na criação do filho foi o fator mais mencionado. Desse modo, percebe-se que houve uma tendência dos pais a valorizarem mais a participação paterna, distanciando-se de características da paternidade tradicional, ainda que essas também estiveram presentes.

A experiência da paternidade foi também influenciada pelo desenvolvimento do bebê e as suas aquisições ao final do primeiro ano de vida (MacAdam et al., 2011). Nesse sentido, os pais relataram uma maior interação com os filhos se comparado ao terceiro mês de vida do bebê (Gonçalves et al., 2013), especialmente no que se refere a conseguir se comunicar melhor com ele. Esses achados vão ao encontro da literatura, que aponta que a paternidade e a satisfação com a mesma ocorre de modo gradual (Brazelton \& Cramer, 1992). Ademais, pode-se pensar que a maior interação dos pais com seus filhos nesta etapa do desenvolvimento proporcionou uma maior satisfação com a paternidade. A partir disso, é plausível se considerar que a criança foi adquirindo outra posição subjetiva frente ao pai, permeando o modo como esse experiencia sua paternidade.

Cabe destacar também que, dentre as características dos filhos que pareciam influenciar na experiência da paternidade, estão os aspectos físicos e de temperamento dos bebês, especialmente quando apontados como semelhantes aos dos pais. Além de os pais atribuírem, em sua maioria, aspectos positivos aos filhos, como serem alegres e sociáveis, foram ainda ressaltados os traços de personalidade mais marcantes pelos participantes. Numa perspectiva psicanalítica, essas características remetem ao narcisismo paterno, enquanto atualizado na relação com o filho (Ferrari, Piccinini, \& Lopes, 2013; Freud, 1914/2004). Pode-se pensar que o bebê foi associado a um prolongamento narcísico, na medida em que a ele foram atribuídos aspectos semelhantes ao próprio pai. Desse modo, o fato de perceber no filho semelhanças consigo mesmo pode ser visto como mais um dos aspectos cruciais na experiência da paternidade e no processo de tornar-se pai.

A experiência da paternidade foi também permeada pelo dia a dia dos participantes com seus filhos. Conforme anteriormente citado, os pais do presente estudo se mostraram participativos nos cuidados e na vida dos filhos. Contudo, o trabalho, para alguns participantes, pareceu ser um fator que restringiu o tempo dedicado à interação com os filhos, com consequências para a própria paternidade (Yavorsky et al., 2015). Em contrapartida, outros pais não associaram o trabalho como um empecilho, distinguindo-se de outros estudos nos quais os participantes relataram desejar participar mais dos cuidados com os seus filhos, o que não era possível devido ao tempo investido no trabalho (Bornholdt, Wagner, \& Staudt, 2007). Nessa perspectiva, esse posicionamento dos pais pode expressar uma distinta organização em relação ao trabalho, bem como ao cuidado com os bebês. Além disso, os pais deste estudo podem ter considerado que o tempo que passavam com seus filhos era suficiente. Quanto às atividades realizadas com os filhos, os pais salientaram preferir brincar e passear com os bebês, em detrimento de cuidados físicos, como trocar fralda e roupas. Outros estudos apontam resultados semelhantes, no sentido de que os pais participam mais nas brincadeiras dos filhos, enquanto as mães priorizam os cuidados em geral (Krob et al., 2009).

Outro aspecto que parece influenciar na experiência da paternidade diz respeito às impressões dos participantes sobre suas esposas como mães e acerca do relacionamento do casal. Conflitos do casal foram mencionados pelos participantes, no que dizia respeito aos cuidados e à educação dos filhos. Esses conflitos revelaram, de certo modo, um papel diferente do tradicionalmente exercido pelos pais neste contexto. Aproximadamente metade dos participantes relatou dividir com a esposa os cuidados com os filhos, o que parecia lhes proporcionar satisfação como pais. Apesar de essas verbalizações apontarem novamente para um modelo de pai mais participativo e envolvido, outros participantes destacaram que as esposas assumiam a maioria dos cuidados. Essa configuração foi atribuída pelo fato de as mães passarem mais tempo com os bebês, assim como pelo entendimento de que suas esposas saberiam cuidar melhor dos filhos.

A respeito disso, compreende-se que esses entendimentos paternos expressam a permanência de papéis tradicionais na dinâmica familiar, o que por sua vez pode influenciar no modo como os 
homens experienciam sua paternidade. Alguns pais descreveram-se como "ajudantes" da esposa, ou seja, como coadjuvantes nos cuidados com o bebê, como já relatado na literatura (Krob et al., 2009; Vieira et al., 2014). Acerca disso, de acordo com Winnicott (1965/1985), é a mãe que possibilita ao pai se relacionar com seu bebê. Com isso, pode-se pensar que pelo menos alguns desses pais que relataram um papel de coadjuvante podiam estar se sentindo "impedidos" por suas esposas de uma maior proximidade com o bebê (Cherer, Ferrari, \& Piccinini, 2016), ao mesmo tempo que isso podia reforçar a crença de que é a mulher quem deve cuidar dos filhos.

\section{Considerações finais}

Os resultados do presente estudo permitiram compreender alguns aspectos da experiência da paternidade ao final do primeiro ano de vida do bebê. Dentre esses, como aos três meses do bebê (Gonçalves et al., 2013), destaca-se a satisfação com a paternidade, relatada pela grande maioria dos participantes, especialmente relacionada ao desenvolvimento da criança. Os pais se relataram como bastante participativos e envolvidos na vida familiar, especialmente no que diz respeito aos cuidados com o bebê. Contudo, o modelo tradicional de paternidade, em que o homem assume prioritariamente o papel do provedor e reconhece a mulher como principal cuidadora do bebê, ainda se fez presente nos relatos dos pais do presente estudo. Esses aspectos evidenciam a diversidade de modos contemporâneos de se experienciar a paternidade, indicando também uma transição nas definições do que é ser pai.

Cabe, entretanto, ressaltar algumas especificidades constatadas na análise de dados do presente estudo. Por exemplo, em sua maioria, os relatos espontâneos dos pais privilegiaram aspectos positivos concernentes à paternidade. Entretanto, de modo sutil e contraditório, a paternidade também se expressou de forma ambivalente, abrangendo aspectos difíceis, como o remanejamento psíquico, demandando dos pais um reposicionamento frente à vida (Chevalerias, 2005; Hurstel, 2006). Além disso, pode-se considerar a dificuldade para muitos homens em expressarem suas experiências subjetivas enquanto pais. Pode-se pensar que os pais falam distintamente de sua experiência do que as mães, talvez, inclusive, porque a valorização da paternidade é algo ainda recente e em construção, sendo plausível considerar que contribui para isso o destaque concedido à maternidade na nossa cultura. Pode-se considerar que o modo como os pais se viam, reorganizaram suas vidas e se posicionavam frente ao bebê e à companheira também está associado a concepções que possuíam a respeito da paternidade. Acredita-se que as novas versões do pai tenham influenciado os modos de subjetivação, especialmente de forma idealizada, preservando, de qualquer modo, elementos considerados tradicionais.

Neste estudo pretendeu-se salientar elementos subjetivos da experiência da paternidade, pondo em destaque elementos comuns e particularidades relatadas pelos pais. Optou-se por evidenciar com porcentagens com o intuito de exemplificar a frequência que esses aspectos surgiam no relato paterno, uma vez que essas permitem considerar a extensão das verbalizações e eventuais comparações dos elementos mais salientados. Nesse sentido, também é importante que se considere com cautela o emprego de recursos quantitativos, como as porcentagens usadas no presente estudo, que devem ser vistas como indicadores da extensão com que determinado relato apareceu entre os pais e não sobre a importância pessoal ou teórica de determinada experiência subjetiva. Ademais, acredita-se que os relatos paternos analisados neste estudo são passíveis de serem reagrupados e reinterpretados, produzindo novos aprendizados sobre a experiência da paternidade.

Por fim, entende-se que, em conjunto, os resultados do presente estudo evidenciaram a complexidade da experiência da paternidade, a qual apareceu associada não só a aspectos subjetivos, mas também ao próprio filho, à esposa, e a outros contextos como o familiar e o cultural. Com isso, destaca-se a necessidade de mais pesquisas sobre a experiência subjetiva do tornar-se pai, inclusive de forma longitudinal, o que poderá contribuir não só para se compreender a relação pai-filho, como para o próprio desenvolvimento da criança.

\section{Referências}

Bouchard, G. (2012). Intergenerational transmission and transition to fatherhood: a mediated-moderation model of paternal engagement. Journal of Family Psychology, 26(5), 747-755. 10.1037/a0029391

Bornholdt, E. A., Wagner, A., \& Staudt, A. C. P. (2007). A vivência da gravidez do primeiro filho à luz da perspectiva paterna. Psicologia Clínica, 19(1), p. 75-92. 
Brazelton, T. B. \& Cramer, B. G. (1992). As primeiras relações. São Paulo: Martins Fontes.

Castoldi, L., Gonçalves, T. R., \& Lopes, R. C. S. (2014). Envolvimento paterno da gestação ao primeiro ano de vida do bebê. Psicologia em Estudo (Maringá), 19(2), 247-259. http://dx.doi.org/10.1590/1413-737222105008

Cherer, E. Q., Ferrari, A. G., \& Piccinini, C.A. (2016). A amamentação e o desmame no processo de tornar-se pai. Estilos da Clínica, 20(1), 1-18. http://dx.doi.org/10.11606/issn.1981-1624.v21i1p12-29

Chevalerias, M. P. (2005). O homem, o filho, o amante: as diferentes figuras do pai em torno do nascimento. In M. D. Moura (Org.). Psicanálise e hospital - novas versões do pai: reprodução assistida e UTI-4 (pp. 21-32). Belo Horizonte: Autêntica/FCH-FUMEC.

Chin, R., Hall, P., \& Daiches, A. (2011). Fathers' experiences of their transition to fatherhood: a metasynthesis. Journal of Reproductive and Infant Psychology, 29(1), 4-18. http://dx.doi.org/10.1080/02646838.2010.513044

Dallos, R. \& Nokes, L. (2011). Distress, loss, and adjustment following the birth of a baby: a qualitative exploration of one new father's experiences. Journal of Constructivist Psychology, 24, 144-167.

Eerola, J. P. \& Huttunen, J. (2011). Metanarrative of the "New Father" and narratives of the Young Finnish first-time fathers. Fathering, 9(3), 211-231. 10.3149/fth.0903.211

Fägerskiöld, A. (2008). A change in life as experienced by first-time fathers. Scandinavian Journal of Caring Sciences, 22(1), 64-71. 10.1111/j.1471-6712.2007.00585.x

Ferrari, A. G., Piccinini, C. A., \& Lopes, R. C. S. (2013). Atualização do Complexo de Édipo na relação com o bebê: evidências a partir de um estudo de caso. Estudos de Psicologia (Campinas), 30(2), 239-248. http://dx.doi.org/10.1590/ S0103-166X2013000200010

Freud, S. (1990). La organización genital infantil (Una interpolación en la teoría de la sexualidade). (J. Etcheverry, Trad.). Em J. Strachey (Org.), Obras completas (Vol. 19, pp. 141-149). Buenos Aires: Amorrortu. (Original publicado em 1923).

Freud, S. (2004). À Guisa de Introdução ao Narcisismo. In S. Freud. Escritos sobre a psicologia do inconsciente (Vol 1, pp. 95-131). Rio de Janeiro: Imago. (Original publicado em 1914).

Gonçalves, T. R., Guimarães, L. E., Silva, M. R., Lopes, R. C. S., \& Piccinini, C. A. (2013). Experiência da paternidade aos três meses do bebê. Psicologia: Reflexão e Crítica, 26(3), 599-608. http://dx.doi.org/10.1590/S010279722013000300020

Guzzo, K. (2011). New fathers' experiences with their own fathers and attitudes toward fathering. Fathering, 9(3), 268-290. 10.3149/fth.0903.268

Höfner, C., Schadler, C., \& Richter, R. (2011). When men become fathers: men's identity at the transition to fatherhood. Journal of Comparative Family Studies, 42(5), 669-686.

Houzel, D. (2004). As implicações da parentalidade. In L. Solis-Ponton (Org.). Ser pai, ser mãe, parentalidade: um desafio para o terceiro milênio (pp. 47-52). São Paulo: Casa do Psicólogo.

Hurstel, F. (2006). "L'annonce faite au mari” ou les trois temps du "devenir père". Adolescence, 24(55), 79-89. 10.3917/ ado.055.0079

Jager, M. E. \& Bottoli, C. (2011). Paternidade: vivência do primeiro filho e mudanças familiares. Psicologia, Teoria e Prática, 13(1), 141-153.

Krob, A., Piccinini, C. A., \& Silva, M. R. (2009). A transição para a paternidade: da gestação ao segundo mês de vida do bebê. Psicologia USP, 20(2), 269-291. http://dx.doi.org/10.1590/S0103-65642009000200008

Laville, C. \& Dione, J. (1999). A construção do saber: manual de metodologia da pesquisa em ciências humanas. Porto Alegre: Artes Médicas.

Leclaire, S. (1977). Mate-se uma criança. Rio de Janeiro: Zahar.

MacAdam, R., Huuva, E. \& Berterö, C. (2011). Fathers' experiences after having a child: Sexuality becomes tailored according to circumstances. Midwifery, 27(5), 149-155. http://dx.doi.org/10.1016/j.midw.2009.12.007

Palkovitz, R. \& Palm, G. (2009). Transitions within Fathering. Fathering: A Journal of Theory, Research \& Practice About Men as Fathers, 7(1), 3-22. 10.3149/fth.0701.3

Parke, R. D. (1996). Fatherhood. Cambrigde: Harvard University Press.

Piccinini, C. A., Silva, M. R., Gonçalves, T. R., Lopes, R. C. S., \& Tudge, J. (2012). Envolvimento paterno aos três meses de vida do bebê. Psicologia: Teoria e Pesquisa, 28(3), 303-314. http://dx.doi.org/10.1590/S0102-37722012000300006

Polli, R. G., Gabriel, M. R., Piccinini, C. A., Lopes, R. C. S. (2016). Envolvimento paterno aos 12 meses de vida do bebê. Psico, 47(3), 198-208. http://dx.doi.org/10.15448/1980-8623.2016.3.23205

Premberg, A., Hellström, A. L., \& Berg, M. (2008). Experiences of the first year as father. Scandinavian Journal of Caring Sciences, 22(1), 56-63. 10.1111/j.1471-6712.2007.00584.x

Vieira, M. L., Bassardi, C. N., Gomes, L. B., Bolze, S. D. A. Crepaldi, M. A., \& Piccinini, C. A. (2014). Paternidade no Brasil: revisão sistemática de artigos empíricos. Arquivos Brasileiros de Psicologia, 66(2), 36-52.

Winnicott, D. W. (1985). E o pai? In D. W. Winnicott. A criança e o seu mundo (pp. 127-133) Rio de Janeiro: Zahar (Original publicado em 1965). 
Yavorsky, J. E., Dush, C. M. K., \& Schoppe-Sullivan, S. J. (2015). The production of inequality: The gender division of labor across the transition to parenthood. Journal of Marriage and Family, 77(3), 662-679. 10.1111/jomf.12189

Dados dos autores:

Evandro de Quadros Cherer - Mestre, Universidade de Brasília.

Joice Cadore Sonego - Doutora, FSG Centro Universitário.

Cesar Augusto Piccinini - Doutor, Universidade Federal do Rio Grande do Sul.

Rita de Cássia Sobreira Lopes - Doutora, Universidade Federal do Rio Grande do Sul.

Endereço para correspondência:

Evandro de Quadros Cherer

Universidade de Brasília, Instituto de Psicologia

Departamento de Psicologia Clínica e Cultura

Campus Universitário Darcy Ribeiro, ICC - Ala Sul, Bloco A, Térreo

70910-900, Brasília, DF, Brasil

<quadroscherer@gmail.com>

Recebido em: 08.02.2017

Aceito em: 22.05.2017 